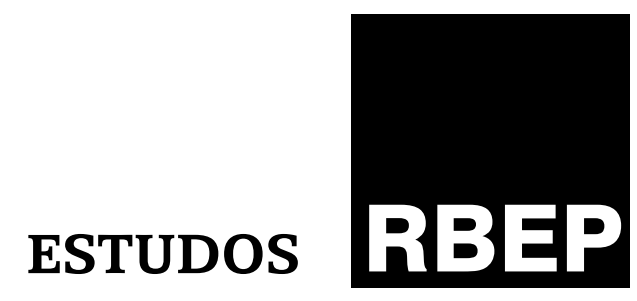

\title{
A constituição dos sujeitos e a produção de conhecimentos: pontuações acerca da pesquisa sobre o livro didático de história*
}

Elicio Gomes Lima

\section{Resumo}

Discute algumas dimensões acerca da pesquisa sobre o livro didático de história e recorre como ponto de partida ao processo de constituição do sujeito que aprende e sua respectiva produção do conhecimento, não simplesmente como output do ideário desejado pelo sistema capitalista. Utilizou-se como dimensão de tratamento do objeto a pesquisa qualitativa, enriquecida por etapas procedimentais centradas em levantamento bibliográfico de literatura especializada da área. O texto conclui que no processo ensino-aprendizagem os sujeitos (educandos, educadores) não se reduzem a meros objetos, mas se constituem uma totalidade histórico-social que se manifesta dinamicamente por meio da linguagem, do contexto social, de suas experiências, construindo e ampliando suas visões de mundo dentro dessa totalidade.

Palavras-chave: pesquisa sobre o livro didático; história; produção de conhecimentos. 
Abstract

The constitution of the subject and the production of knowledge: scores about the research on the history textbook

The article discusses some dimensions about the research on the history textbook, used as a starting point to the process of constitution of subject learning and its production of knowledge, not simply as output desired by the capitalist system. Used as dimension processing object to qualitative research, enriched by procedural steps focused on bibliographic specialized literature in the area. The text concludes that in teachinglearning process the subject (students, educators), does not reduce to mere objects, but if you are in a social-historical totality that manifests itself dynamically through language, social context, their experiences, building and expanding their world views within this totality.

Keywords: research on the textbook; history; production of knowledge.

\section{Introdução}

Ao longo do tempo, observou-se que a lógica da dimensão positivista para o estudo e compreensão dos fenômenos humanos, embora validada por correntes diversas, não apresentava em si uma suficiência que conta de estudar diversidades e multiplicidades, tendo em vista as distintas perspectivas do homem em ler o mundo e ressignificá-lo. Isso concorreu para entendimento de que:

Se a noção de conhecimento se diversifica e multiplica ao ser considerada, podemos supor legitimamente que contém em si diversidade e multiplicidade. Desta forma, o conhecimento já não poderia ser reduzido a uma só noção como informação, percepção, descrição, ideia ou teoria, entretanto, há a necessidade de concebê-lo nos diversos modos ou níveis aos quais corresponderia cada um desses termos. (Morin, 1988, p. 19-20).

A pesquisa histórica é um processo de interpretação de fenômenos históricos, tendo como base um referencial que lhe dê sustentação; portanto, tal tarefa impõe ao pesquisador a incumbência de fundamentar seu marco teórico a partir de observações e interpretações de uma dada "realidade", além de considerar e lançar mão de teorias já construídas anteriormente. A orientar-se por esse pressuposto, o pesquisador deve fundamentar as bases epistemológicas da pesquisa eleita e explicitar a "lógica histórica", isto é, o método dialogal entre hipóteses (categorias e conceitos) de um lado e evidências (dados empíricos) de outro: 
Por "lógica histórica", entendo um método lógico de investigação adequado a materiais históricos, destinados, na medida do possível, a testar hipóteses quanto à estrutura, causação etc., e a eliminar procedimentos autoconfirmadores ("instâncias", "ilustrações"). O discurso histórico disciplinado da prova consiste num diálogo entre conceito e evidência, um diálogo conduzido por hipóteses sucessivas, de um lado, e a pesquisa empírica, do outro. O interrogador é a lógica histórica; o conteúdo da interrogação é uma hipótese (por exemplo, quanto à maneira pela qual os diferentes fenômenos agiram uns sobre os outros); o interrogado é a evidência, com suas propriedades determinadas. (Thompson, 1981, p. 49).

Por meio do diálogo entre sujeito (que comporta múltiplas dimensões em sua compreensão de homem e de mundo) e objeto (que tem evidências ou não), é possível o questionamento em relação às visões, que negam ou comprovam o envolvimento do sujeito historicamente situado no ato de sua produção de conhecimento, de sua relação com o conceito de verdade, sociedade, política, educação, entre outros, e também a problematização de concepções históricas nas quais o pesquisador pode se ancorar para indagar das leituras sua validade, delimitação e atualidade ou não frente a algumas analogias que apresentam pistas distintas e novas.

Sob esse olhar, este artigo se propõe a discutir algumas dimensões que apresentam pistas e devem ser consideradas, acerca não somente do livro didático de história, mas também de como, inclusive por meio dele, a constituição do sujeito que aprende e sua respectiva produção do conhecimento podem se encaminhar. Utilizou-se como dimensão de tratamento do objeto uma pesquisa de cunho qualitativa, enriquecida por etapas procedimentais centradas em levantamento bibliográfico de literatura especializada da área (Morin, 1988; Thompson, 1981; Foucault, 2000; Freire, 1997; Elias, 1994; Vygotsky, 2000; Zamboni, 2001; Piaget, 1997, 1973, 1977, 1983; Freitag, Mota, Costa ,1997; Galzerani, 1988).

Esse texto está organizado em quatro seções: sobre a constituição dos sujeitos; as dimensões dos sujeitos e a produção de conhecimentos - escolares; a ressignificação dos saberes historicamente acumulados; e aspectos ideológicos nos livros didáticos: alguns olhares.

Entende-se essa organização como uma proposta de leitura do objeto, por meio da qual o pesquisador que estuda o livro didático no Brasil pode desdobrar outras inúmeras leituras sobre a área.

\section{Sobre a constituição dos sujeitos}

À medida que o sujeito cognoscente infere e reflete sobre a construção do conhecimento, o mundo e o próprio homem se mostram ressignificados em suas múltiplas manifestações, de forma específica, quando nos reportamos ao processo ensino-aprendizagem na instituição escolar. Mesmo na responsabilização de sua finalidade, a escola e seus professores, ao se debruçarem sobre a educação como ato político, devem permanentemente primar pela emancipação do sujeito, instrumentalizando-o, entre outros, com provocações sobre a 
possibilidade de se enxergar as políticas explícitas, aquelas que direcionam e estabelecem os direitos e avanços sociais e também aquelas que, embora não previstas, por conta de determinados ideários, são frequentemente materializadas. Portanto, o ator social poderá ocupar uma projeção para além de uma formação perfilada ao consumismo, isto é, como sujeito leitor do mundo apresentar-se como produtor de conhecimento na relação com as "coisas" das quais fala e das quais ouve também. Nessa direção, as "palavras" ditas fazem sentido em relação às "coisas" das quais se falam.

Nas pegadas de Thompson (1981), a verdade existe (elementos objetivos), mas de forma relativa, sustentada pela visão do sujeito historicamente datado (verdade relativa). Nessa perspectiva, questões como resistências, contradições, continuidades, rupturas, conflitos e relações de poder expressam implícita e explicitamente algumas vozes, algumas ideologias presentes no livro didático, focalizando a relação texto/ contexto, organizada por produtores dessas obras, entre os quais: o autor, o ilustrador e a editora.

Nesse mesmo contexto que envolve o processo de captar as especificidades da "realidade" social (educacional), coloca-se em discussão o papel da escola, a mediação do educador e o educando como sujeito envolvido na produção e socialização do conhecimento. Assim, as "realidades" solicitam um tratamento em rede para se captar e entender direções e desvios em suas múltiplas dimensões que envolvem as relações, bem como o espaço no qual se situam.

Nesse sentido, fazem parte das "realidades" nossos valores, símbolos, representações mentais, crenças, como também as práticas sociais que desenvolvemos e os condicionamentos circunscritos na ordem social que passam, em maior ou menor grau, por transformações ao longo do processo histórico-social. Embora tudo isso faça parte das práticas sociais, tal asserção pode torna-se mais compreensível para as práticas pedagógicas (processo ensino-aprendizagem) se voltarmos o olhar a uma análise reflexiva dos livros didáticos.

Essa análise tem a potencialidade de permitir, confrontar limites e desvelar condicionamentos nas relações humanas situadas na tessitura discursiva dos livros didáticos, e, à medida que os atores sociais são provocados a indagar seus arranjos, também são possibilitadas distintas leituras, com isso pode ocorrer o fortalecimento do grau de autonomia (relativa) dos sujeitos envolvidos na busca de alternativas às reflexões acerca das produções de conhecimentos histórico-educacionais. Sob esse olhar, o empoderamento dos atores sociais é constituído não somente pelo conhecimento de um novo mundo ou de uma nova leitura que faz da realidade pontos importantes e imprescindíveis no processo de desvelamento epistemológico, mas também por sua perspectiva de intervenção no contexto social e, no caso dos que desenvolvem a pesquisa científica sobre esse quadro, as análises que compõem a visão de conjunto do objeto e concorrem para o seu estado.

De acordo com esse ponto de vista, Foucault (2000) afirma que o poder não é característico de uma classe ou de uma elite dominante, mas 
permeia todos os aspectos da vida social, como uma rede, infinitamente complexa de micropoderes; o poder é tática, manobra, dispositivo de negociação, jogo de interesse, meio para atingir um fim determinado:

O fundamental seria a força da proibição. Ora, creio ser esta uma noção negativa, estrita e esquelética do poder que curiosamente todo mundo aceitou. Se o poder fosse somente repressivo, se não fizesse outra coisa a não ser dizer não você acredita que seria obedecido? O que faz com que o poder se mantenha e que seja aceito é simplesmente que ele não pesa só como uma força que diz não, mas que de fato ele permeia, produz coisas, induz ao prazer, forma saber, produz discurso. Devese considerá-lo como uma rede produtiva que atravessa todo o corpo social muito mais do que uma instância negativa que tem por função reprimir. (Foucault, 2000, p. 8).

Ao interpretar os estudos de Foucault como relação de poder, percebe-se que o poder pode ser entendido como ambíguo, ambivalente, não linear; esse conceito contribui para a construção de visão de mundo em que o sujeito (educando, educador, sociedade) poderá atuar por meio de estratégias de confronto, ou seja, dentro de uma rede dinâmica de correlação de forças. É certo que essa visão de sujeito resistente e ativo não predomina na maior parte da obra de Foucault, contudo, em suas últimas obras - História da sexualidade I e II, é possível detectarmos relações em que os sujeitos são capazes de alterar os rumos do vivido. Em certa medida, para Pedro Demo (2002 p. 17) já aparece com bastante clareza a imagem de que :

A história pode comprovar facilmente que os comandados, desde que possuam um mínimo de percepção crítica, lutam por espaço próprio... Nenhum poder consegue ser, na prática, absoluto. A prova mais contundente disso é que todo poder inventa ideologias de justificação, não só porque lhe parece importante fazer um discurso laudatório, mas, sobretudo, porque teme que os comandados se metam a contestar.

Dentro dessa lógica, o processo educativo e, no interior dele, o material didático utilizado (todo e qualquer tipo de material didático) e as experiências dos sujeitos (educando e educador) devem ser reconhecidos como um conjunto complexo de relações de poder que se transforma e se mantém, simultânea e concomitantemente, capaz de revelar de que modo o sistema social se ajusta e como os seus participantes percebem a si próprios e ao mundo exterior.

Por essas razões, compreende-se que existe uma conjuntura a ser lida e que, não raras vezes, é "naturalizada" por consentimentos irrefletidos, por conta de ocultamentos ou reforços de ideologias em sentido restrito. Tal compreensão exige um esforço na problematização das relações sociais que não acontecem simplesmente de forma despretensiosa, ao contrário, as intencionalidades acompanham a dinâmica de suas projeções, quer explícita, quer implicitamente. A esse respeito, Thompson (1981) fornece alguns elementos para a análise das relações sociais, em que o conceito de classe social é apresentado como categoria histórica e, nela, os sujeitos 
se inter-relacionam ao longo do tempo, não apenas no aspecto econômico, mas também nas dimensões político-culturais. Portanto:

Aquelas proposições do materialismo histórico que influem sobre a relação entre ser social e consciência social, sobre as relações de produção e suas determinações, sobre modos de exploração, luta de classes, ideologia, ou sobre formações capitalistas sociais e econômicas, são (num polo de seu "diálogo") derivadas da observação do suceder histórico no tempo. Não se trata da observação de fatos isolados em série, mas de conjuntos de fatos com regularidades próprias; da repetição de certos tipos de acontecimentos; da congruência de certos tipos de comportamento em diferentes contextos - em suma, das evidências de formações sociais sistemáticas e de uma lógica comum do processo. Essas teorias históricas na medida em que surgem (não por si mesma, mas, no outro polo do diálogo, por trabalhosa conceptualização) não podem ser testadas, como frequentemente se supõe, impondo-se uma interrupção ao processo, "congelando" a história, e tomando uma seção geológica estática, que mostrará o capitalismo ou as hierarquias de classe em qualquer momento dado do tempo, como uma estrutura elaborada. [...] dentro de cada seção aparentemente estática, encontrarse-ão contradições e ligações, elementos subordinados e dominantes, energias decrescentes ou ascendentes. (Thompson, 1981, p. 58).

Pode-se perceber que Thompson (1981), Demo (2002) e Foucault (2000) apresentam em comum, entre outros pontos, um método de produção de conhecimento histórico, cujo itinerário enfatiza pelo menos três dimensões:

- As relações entre sujeito e objeto no ato da produção de conhecimento.

- As relações dialéticas entre cultura e sociedade, muitas vezes deixadas de lado por um olhar metodológico economicista, reducionista.

- As relações dialéticas entre dominação e resistências.

A despeito de algumas políticas serem efetuadas por policymakers, ao ponto de não se fazerem objeto de discussão coletiva com a sociedade, à medida que são implementadas, os atores sociais que as implementam, bem como aqueles para quem elas se direcionam, por vezes não as aceitam em seu formato original, isto é, se encontram fecundidade em seu propósito, a sua efetivação somente se dará quando legitimada pelas intervenções das leituras sociais desenvolvidas. Na mesma correlação, as produções didáticas podem tomar contornos distintos na medida em que os atores sociais percebem sua (des)estrutura, intencionalidades, relações de poder, representações e leituras possíveis que são reforçadas e que precisariam ser repensadas numa lógica de ambiência democrática propriamente dita. Infere-se desse olhar que é necessário se trazer à luz as dimensões dos sujeitos na produção dos conhecimentos escolares que certamente podem influir sobre os rumos da leitura da história, de mundo e do próprio homem. 


\section{As dimensões dos sujeitos e a produção de conhecimentos - escolares}

O conhecimento pode construir-se na pluralidade de vozes no interior de um eixo comum, em que os sujeitos estão circunscritos ao tempo e ao espaço, dialogando, construindo e ressignificando suas leituras de mundo de maneira relacional (conforme propõem as reflexões de Thompson).

Assim, as escolhas, as decisões e as posições tomadas pelos sujeitos têm dimensões sociopolíticas e desempenham papéis fundamentais nos movimentos de transformações da sociedade, no âmbito tanto da dimensão individual como da social. Logo, no enfrentamento, na discussão de conflitos e na tomada de decisões (por educadores e educandos), os conhecimentos escolares são ressignificados, isto é, com potencialidades de desvelar as contradições apresentadas no processo de desenvolvimento da práxis pedagógica.

Nesse sentido, a educação sistematizada não pode ser tomada como matriz única e suficiente para pensar a educação como um todo: trocas entre áreas de conhecimento, contribuições da ciência que a escola fala, mas comumente não se aproxima; experiências sociais nacionais e internacionais que vão além do saber tradicionalmente estabelecido. É necessário reconhecer a capacidade dos sujeitos em romperem com modelos preestabelecidos e a oportunidade de interação social oferecida pela escola, mas também para além dela, pois antes de ler a palavra o indivíduo lê o mundo.

Não é por outro caminho, se não pela interação desses quadros, que aprender do mundo também é aprender e fazer o mundo. Pensar numa educação que emancipa os sujeitos, que lhes confere possibilidades de ser melhores a cada dia, mais humanos, e que primem por sua vocação "ontogenética" não é o caminho que presume o arranjo do capital, presente na atualidade tão fortemente por meio do processo de reestruturação produtiva. Compreende-se, no entanto, que está aí uma direção para, pelo menos, colocar-se como desafio ao homem, ao professor diário, ao educador que se compromete não com a fabricação de homens, dada a roteirização de sua tipologia para a esteira que se quer, mas por sua capacidade de se libertar ao mesmo tempo que contribui para a libertação dos outros. Paulo Freire (1997, p. 12) nos traz subsídios para pensarmos uma educação para a decisão e para a libertação, expressa nesta citação:

Se os seres humanos fossem puramente determinados e não seres "programados para aprender" não haveria por que, na prática educativa, apelarmos para a capacidade crítica do educando. Não haveria por que falar em educação para a decisão, para a libertação. Mas, por outro lado, não haveria também por que pensar nos educadores e educadoras como sujeitos. Não seriam sujeitos, nem educadores, nem educandos, como não posso considerar Jim e Andra, meu casal de cães pastores alemães, sujeito da prática em que adestram seus filhotes, objeto daquela prática. Falta-lhes a decisão, a faculdade de, em face de modelos, romper com um e optar por outro. 
Nessa assertiva, evidencia-se que o processo de formação dos sujeitos, as visões de mundo, não é construído somente ao longo do processo de escolarização, mas por um conjunto complexo de relações e de experiências que ocorrem ao longo de sua existência. Nesse sentido, no diálogo com as reflexões de Thompson, a concepção do conceito de experiência dos seres humanos, situados num sistema complexo, cercados de formas simbólicas de dominação e de resistências, baseia-se na interrelação social, situada num dado espaço, num dado tempo:

E quanto à "experiência" somos levados a reexaminar todos esses sistemas densos, complexos e elaborados pelos quais a vida familiar e social é estruturada e a consciência social encontra realização e expressão: parentesco, costumes, as regras visíveis da regulação social, hegemonia e diferenças, formas simbólicas de dominação e de resistências. (Thompson,1981, p. 189).

Daí, então, afirma-se que a consciência social não é algo cristalizado, acabado, petrificado ou implantado no sujeito a bel-prazer de outrem. Assim, as visões de mundo, tanto do educando como do educador, inseridas no processo ensino-aprendizagem são construídas a partir de um movimento dialético, engendrado numa rede de relações, decorrentes das condições de vida, num dado espaço e num dado tempo. Os homens não se reduzem a seres passivos, incapazes de perceber as contradições e rupturas que permeiam seu espaço circunstancial, eles estão inseridos em uma rede social e envolvidos por um conjunto de múltiplas relações.

Como seres históricos, os sujeitos produzem e acumulam conhecimentos como também se relacionam, mobilizam-se na história e com a história, ou seja, os sujeitos são capazes de inteligir o mundo e nele atuar. Essa mobilidade histórico-dialética possibilita e habilita-o a compreender e a perceber (consciência) traços essencialmente contraditórios, assim como as constantes transformações que ocorrem no universo social.

Por outro lado, essa consciência opera o ser e o fazer, compromete-se com a sua existência na relação com o social, podendo operar transformações que podem ser conduzidas para fora dos limites do reducionismo, abrindo janelas para as superações das verdades cristalizadas e para ampliar as dimensões espaciais e temporais dos sujeitos. Nessa direção, pensar no educando, construído só pelo material didático, é atrelar-se a uma visão unilateral, que concebe os sujeitos envolvidos no processo ensino-aprendizagem unicamente como objetos, que caminham para a homogeneização, cristalizando saberes transmitidos e valores impostos pelas classes dominantes constituídas.

Essa visão encobre os embates, as superações, as legitimações, as conquistas individuais e coletivas, bem como os limites e condicionantes das relações de poder, existentes no interior das classes e nas interações humanas historicamente dadas. Uma vez que a interação dialógica desenvolvida na dimensão de espaço e tempo escolar na relação com o livro didático pode abrir possibilidades para o desenvolvimento das 
potencialidades e permitir que as experiências possam também ser compartilhadas, anuncia-se uma visão diferenciada de ser ator social, como ser produtor de conhecimentos escolares, dotado de autonomia e de criatividade.

Por meio de suas experiências, educandos, educadores e agentes das práticas do cotidiano escolar demonstram que os sujeitos, ao longo do processo de escolaridade e da própria vida, desenvolvem capacidades de analisar fatos, acontecimentos e decisões político-sociais historicamente situados.

Vygotsky (2000, p. 81) chama a atenção para o conceito de desenvolvimento proximal, ou seja, para a capacidade da criança dar saltos qualitativos, sob o ponto de vista cognitivo, com a ajuda do outro (seja o professor, o colega, os pais ou os vizinhos), inserida em um processo de interação, em que ela transforma o olhar sobre o objeto, ampliando-o e possibilitando, ao mesmo tempo, alterações nas práticas sociais. Nesse sentido, a sociedade, a escola e o livro didático são espaços de tensões, conflitos e embates, evidenciando que a produção dos saberes escolares é um processo constituído por múltiplas relações dos sujeitos com o social.

Mas não podemos esquecer que presentes nas múltiplas relações e no processo histórico estão os condicionantes, os limites, a autonomia, mesmo que relativa, e as possibilidades que interferem nas condições materiais de existência dos sujeitos.

Portanto, embora estejam ligados a situações específicas que envolvem tanto educandos como educadores, os seres humanos são capazes de pensar, refletir, agir e compreender o mundo, construindo e (re)significando sentidos na participação e nas transformações das realidades que os cercam.

Desse modo, os seres humanos reúnem a possibilidade de fazer escolhas, de fazer opções, de julgar, o que implica, necessariamente, comparar e valorar objetos e situações contextuais. Logo, essas escolhas, opções e julgamentos definem-se por um ou mais posicionamentos diante de um conjunto de valores, que não foram estabelecidos por um único indivíduo, mas no contexto das relações com outros seres humanos. Assim, nesse amálgama social, tecendo relações com grupos e classes sociais nas quais estão inseridos, os sujeitos desenvolvem potencialidades.

Por esse viés, os sujeitos desempenham papéis ativos e essenciais na construção de sua própria história e na definição de sua própria identidade cultural. Norbert Elias (1994) classifica esse movimento dialético dos sujeitos no universo social como uma rede de inter-relação. Segundo ele:

Para ter uma visão mais detalhada desse tipo de inter-relação, podemos pensar no objeto de que deriva o conceito de rede: a rede de tecido. Nessa rede, muitos fios isolados ligam-se uns aos outros. No entanto, nem a totalidade da rede nem a forma assumida por cada um de seus fios podem ser compreendidas em termos de um único fio, ou mesmo de todos eles, isoladamente considerados; a rede só é compreensível em termos da maneira como eles se ligam, de sua relação recíproca. Essa ligação origina um sistema de tensões para o qual cada fio isolado concorre, cada um de maneira um pouco diferente, conforme seu lugar 
e função na totalidade da rede. A forma do fio individual se modifica quando se alteram a tensão e a estrutura da rede inteira. No entanto essa rede nada é além de uma ligação de fios individuais; e, no interior do todo, cada fio continua a constituir uma unidade em si; tem uma posição e uma forma singular dentro dele. (Elias, 1994, p. 35).

Pode-se afirmar que os problemas enfrentados no cotidiano dos sujeitos podem provocar e estimular criatividades, na busca de soluções para resolvê-los. Assim, o pensar, o refletir a ação desenvolve gradativamente a capacidade de "autonomia", ou seja, pode construir sujeitos que problematizam as circunstâncias pessoais e coletivas das comunidades nas quais se inserem, e na sociedade global. O sentido de sua ressignificação não se dá por meio de parâmetros preestabelecidos, mas do entendimento de que a história que se conta, da qual se fala e se é condicionado a aprender é a sua própria, daí o chamamento para sua tomada de lugar como ator social.

A problematização docente pode se constituir como um rico provocador nesse âmbito, portanto, na inter-relação do processo ensinoaprendizagem, cabe ao educador problematizar o conteúdo e a forma de uso do material didático, convidando em cada momento do ato educativo o educando a interagir, a dialogar com os textos e a levantar hipóteses sobre temas, relacionando-os e comparando-os com outros pontos de vista, uma vez que o mais "[...] importante é que o professor se acostume a problematizar o conteúdo, porque cria condições para o aluno pensar sobre ele, argumentar e fundamentar suas opiniões" (Zamboni, 2001, p.10).

\section{A ressignificação dos saberes historicamente acumulados}

O conhecimento é socialmente produzido, isto é, caracteriza-se como um processo marcado por diversos condicionantes sociais, tanto objetivos como subjetivos. Isso significa que, apesar das limitações de ordem social, ideológica e política que se interpõem na concretização da produção do conhecimento, essa construção ocorre como processo dialético, sempre aberto a potencialidades e possibilidades ${ }^{1}$ dos sujeitos em busca de "autonomia".

Autonomia aqui entendida como capacidade não só de julgar valores comprometidos com interpretações particulares e interesses de grupos sociais hegemônicos que tentam prevalecer sobre os interesses sociais, mas de saber que na própria trama do ato de conhecer existem visões além e aquém sobre o estudo do objeto.

Entende-se por conhecimento socialmente produzido aqueles derivados da transformação no modo de produção, na estrutura social, na família como instituição e na produção e difusão de significados no tempo e no espaço dos bens materiais e não materiais.

Portanto, o conhecimento não é algo situado fora dos sujeitos, como também não se constrói independente da interação com o meio social - é um processo interativo histórico-social, no qual múltiplos fatores 
interferem na formulação de diretrizes orientadoras das ações dos sujeitos. Assim, os conhecimentos resultam de interações que se produzem entre sujeitos e objetos, mediante uma organização de ações sucessivas exercidas sobre os objetos a serem conhecidos (Jean Piaget), isso demanda o conhecimento sobre o real (ação), a indagação e pontuações sobre o nível de validade entre aproximações e distanciamentos (reflexão) e finalmente um encaminhamento ressignificado (ação revisitada), perfazendo a trilogia ação-reflexão-ação.

O que institui os conhecimentos, portanto, é a assimilação e acomodação cognitiva dos objetos, sucessivas percepções, associações, as ações e o pensamento reflexivo. Nesse sentido, o desenvolvimento mental é uma construção progressiva que procura compreender e explicar seu entorno em função dos interesses dos sujeitos.

Para Piaget (1997, 1973, 1977, 1983), a inteligência é um processo de sucessivas adaptações e equilibrações entre assimilação e acomodação no qual a função simbólica pode evocar o passado, o presente e antecipar as ações do futuro. Não é propósito deste trabalho tratar sobre a gênese da inteligência, entretanto, não existe fecundidade em se pesquisar como os sujeitos ressignificam o conhecimento historicamente situado sem delimitar a base conceitual da formação da inteligência que se crê válida para sua leitura. Nessa direção, os sujeitos no estágio das operações formais podem construir o pensamento conceitual e conciliar seus próprios interesses e os dos grupos a que pertencem ou ao qual estão filiados. Nessa perspectiva, os sujeitos (educadores e educandos) são capazes de mobilizar diferentes saberes para agirem em situações de aprendizagem por eles realizadas.

Daí a necessidade de se refletir e encarar tais saberes como um processo global e complexo, no qual conhecer e intervir em uma dada "realidade" são movimentos que não se dissociam, ou seja, o processo de aprendizagem vincula-se ao mundo fora da escola, e os saberes escolares perpassam as relações que as disciplinas e os conteúdos podem estabelecer entre si. No que refere à mediação escolar, no processo de busca de resultados e assimilação de conhecimentos sistematizados, a instituição deve primar por desenvolver um conjunto de condições metodológicas e organizativas que, intrínsecas as relações sociais, possam constituir elementos concretos para uma aprendizagem significativa.

Dessa forma, práticas sociais próprias da complexidade da vida escolar, permeadas pelas relações sociais e por jogos simbólicos, produzem significados que dão sentidos às ações pedagógicas, aos procedimentos pedagógico-didáticos, às expectativas de comportamentos e às normas, instituindo uma cultura específica na educação escolar - a cultura escolar. Os saberes escolares efetivam-se quando os sujeitos (educandos e educadores) apropriam-se desse espaço cultural e o reelaboram no seu cotidiano. É nesse contexto que emerge o termo que se utilizou conhecimentos escolares.

De forma mais abrangente, o termo vincula-se ao conjunto das características próprias da vida escolar, e a força interpretativa do termo 
advém da possibilidade de agregar, aos saberes disciplinares, outros saberes que podem ser articulados ao contexto sociopolítico no interior da escola, como situações desafiadoras que favorecem o desenvolvimento da capacidade de discernir e analisar diferentes aspectos do passado e do mundo contemporâneo.

Compreendendo a existência de vínculos interdisciplinares entre as várias facetas do processo de aprendizagem, falo de conhecimentos histórico-escolares enquanto instrumento de aprendizagem, matriz que embasa os elementos da disciplina de história, nos seus conteúdos, nos recursos metodológicos, na relação aluno-professor e na relação com o meio social no qual educandos e educadores estão inseridos - processo este que não se esgota em si mesmo.

Portanto, são saberes organizados e dispostos especificamente para fins de ensino-aprendizagem, não como mera transposição didática (Chevallard, 1991) do saber/fazer de referência para a sala de aula apenas, mas como elementos culturais em que a matéria de ensino se vincula aos saberes escolares como um todo e deve ser entendida como um processo que envolve múltiplas relações (o múltiplo-disciplinar e social). Em outras palavras, os conhecimentos histórico-escolares, aqui compreendidos, são marcos referenciais didaticamente assimiláveis no âmbito do ambiente escolar enquanto instrumentos teóricos que vão além da organização da matéria, ligando-se às práticas da vida cotidiana de educandos e educadores, ou seja, constituem domínio de conhecimentos básicos, os quais passam do "senso comum" aos conhecimentos "científicos", que podem possibilitar ao aluno refletir sobre as conexões das matérias e conteúdos escolares com os problemas do meio social, produzindo dimensões mais abrangentes. Portanto, conceber conhecimento históricoescolar num processo dialógico, com múltiplas relações, transcende os limites de uma disciplina escolar e possibilita analisar os problemas, os fatos, os acontecimentos e as situações dentro de um contexto de relações socioculturais historicamente mais amplo.

\section{Aspectos ideológicos nos livros didáticos: alguns olhares}

De acordo com informações do catálogo analítico "O que sabemos sobre o livro didático", publicado pelo Serviço de Informação sobre o Livro Didático da Universidade Estadual de Campinas (Unicamp) em 1989, e da obra "O livro didático em questão" (Freitag, Motta, Costa, 1987), tem-se um número considerável de estudos no Brasil sobre o livro didático que tratam do processo de assimilação e percepção do seu conteúdo pelo educando.

Freitag, Mota e Costa (1997, p. 65) observam que praticamente "todos os estudos realizados no Brasil sobre o livro didático têm como dimensão de análise o seu conteúdo com as mais variadas ênfases" e que "esses trabalhos são unânimes em ressaltar que a ideologia contida no livro didático serve para consolidar a hegemonia das classes dominantes e com ela as relações de produção" (p. 86). 
Tais análises foram produzidas no Brasil nos anos de 1970 e 1980, como fruto da incorporação da metodologia de análise materialista histórico-dialética. Tiveram o mérito de relacionar os textos didáticos ao sistema no qual foram produzidos, ou seja, ao sistema capitalista. Nesse sentido, trazem a contribuição da problematização dos conteúdos didáticos como instrumento ideológico, a serviço dos interesses de perpetuação das visões das classes dominantes no Brasil. De múltiplas leituras, entende-se que outras questões poderiam ser acrescidas, as quais podem trazer, ao estudante e ao professor, o entendimento de que o processo de construção do conhecimento não se dá na contemporaneidade somente por uma mão, entre elas destacamos:

- Até que ponto alguns desses livros didáticos focalizam as relações sociais e as lutas de classes como sendo determinadas somente pela relação capital e trabalho (relações econômicas)?

- Em que medida, em algumas dessas obras, a escola é visualizada como transmissora dos valores da elite dominante, o educando como um ser submetido passivamente às intempéries ideológicas da classe dominante e o educador como um instrumento que reforça e reproduz o poder dos dominadores?

- Até que ponto, em tais obras, o Estado é apontado como um mecanismo que defende os interesses exclusivamente da classe dominante (o interesse da elite é o da nação)?

Tal perspectiva acima problematizada, em nossa visão, oblitera a dinâmica dialética do movimento entre a escola, o professor, o educando, os textos didáticos, assim como o papel do Estado, negando a ambiguidade e a ambivalência que penetram essas relações sociais. Além disso, essa perspectiva não considera e não vê o professor como sujeito, capaz de ressignificar o conteúdo apresentado no livro didático, de forma que sua análise crítica possa dar outro sentido ao texto trabalhado em sala de aula.

Outro agravante pertinente a essa perspectiva analítica é a de desprezar a capacidade cognitiva do educando, como também sua experiência de vida. Logo, nessa ótica, não são levadas em conta as relações entre professores, textos, alunos e "realidades" vivenciadas no processo ensino-aprendizagem. Cremos que o processo educativo não pode ser apresentado de maneira mecânica, uma vez que o Estado, a escola, o educador, os materiais didáticos, a família, a religião e muitos outros meios são instrumentos que podem instigar e promover no aluno sua capacidade de estabelecer "novas" relações, a partir das experiências vividas.

Portanto, concordamos com Galzerani quando em um de seus artigos "Belas mentiras? Ideologia sobre o livro didático," produzido no final dos anos 80 no Brasil, chama a atenção para uma análise dos livros didáticos, capaz de trazer à tona não uma visão unidimensional, mas as contradições sociais. 
Se consideramos o livro didático em sua relação dialética com a sociedade, e se concebemos a sociedade em conflito, plena de contradições, mesmo admitindo e até reforçando a tese da manutenção do "ethos capitalista" que seu conteúdo muitas vezes tem por objetivo, perguntamos até que ponto podemos afirmar que o livro didático contém apenas "mentiras", que correspondem diretamente à reprodução das relações de produção. Não conteriam também outros elementos relacionados a outras visões da sociedade, absorvidos e apresentados pelo autor da obra, até mesmo para garantir sua aceitação por uma parcela mais ampla da população? Em outras palavras, até que ponto o conteúdo do livro didático constitui apenas uma máscara que impede o conhecimento da vida social? Ou será que sua linguagem contraditória e ambígua não só esconderia como também expressaria os conflitos da sociedade? (Galzerani, 1988, p. 107).

No assentimento dessa proposição, enfocamos que no processo ensino-aprendizagem os sujeitos (educandos, educadores) não se reduzem a meros objetos, mas se constituem em uma totalidade histórico-social que se manifesta dinamicamente por meio da linguagem, do contexto social, de suas experiências, construindo e ampliando suas visões de mundo dentro dessa totalidade.

Nesse sentido, apontamos para outros caminhos à luz de Thompson, Vygotsky, Foucault, entre outros, que conceituam as relações sociais como frutos de movimentos contraditórios que coexistem numa totalidade histórico-cultural, em que os condicionamentos podem ser vistos como limites sempre abertos à contestação e à superação.

Tais autores potencializam visões sobre o livro didático, ${ }^{2}$ em que a dimensão das relações dialéticas constitui a base fundante da reflexão, ponto central de nossas considerações em próximo estudo.

\section{Considerações finais}

As relações dos sujeitos com objetos, com ideias, com o presente, com as vivências e com experiências individuais e coletivas estabelecem nexos na construção da sua visão de mundo. Portanto, essa lógica relacional os potencializa enquanto seres em formação na construção de seus próprios conhecimentos, à medida que desenvolvem sua individualidade e a visão das contribuições coletivas a partir não somente da aquisição de informações históricas sistematizadas e intermediadas pelos professores em sala de aula e das totalidades percebidas em seu contexto sociocultural, mas de suas leituras e intervenções próprias de sujeitos sócio-históricos.

Assim, a partir de uma concepção dialética (que relaciona a leitura dos textos históricos às experiências socioculturais dos educandos), pode-se compreender o processo ensino-aprendizagem como um caminho que possibilita a "formação" da consciência dos sujeitos enquanto educandos, enquanto seres humanos, capazes de pensarem, agirem e interpretarem o mundo segundo suas convicções e crenças, mediado pelas interações dos professores e em dimensões mais abrangentes que interligam todos os conhecimentos com a cultura escolar. 
Nessa confluência, percebe-se que os livros didáticos em suas múltiplas relações e nas mais variadas dimensões podem ser instrumentos capazes de desencadear o desenvolvimento da autonomia (relativa) dos educandos como sujeitos que têm possibilidades históricas de compreenderem e atuarem no mundo, desde que os educadores em seu trabalho desenvolvam e tenham consciência que precisam "formar" sujeitos politicamente situados, capazes de compreenderem a dinâmica social e atuarem politicamente rumo às transformações sociais, se necessário para além da própria escola.

Ao mesmo tempo, a complexidade das relações humanas, nas mais variadas circunstâncias e situações, evidencia que os sujeitos em um mesmo contexto sociocultural podem ter diferentes posicionamentos e percepções das formas de encaminhamentos das práticas sociais, das atitudes, do modo de agir, de pensar e de avaliar os fatos e acontecimentos da vida cotidiana e até mesmo o papel das relações em enfoque globalizador.

São essas evidências que podem ajudar a explicar e a compreender as relações de poder e as ideologias nos mais diversos seguimentos sociais (escola/livro didático) e na sociedade como totalidade. É nesse processo que configuram as tensões e conflitos que têm uma representação e pretensão de mudanças e comprometimento, que implicam adesão, escolhas e estabelecimentos de novos ou outros caminhos.

\section{Referências bibliográficas}

BATISTA, Antônio Augusto Gomes. Um objeto variável e instável: textos, impressos e livros didáticos. In: ABREU, Márcia (Org.). Leitura, história e história da Leitura. Campinas, SP: Mercado das Letras, 2002.

BITTENCOURT, Circe M. Fernandes. O livro didático e conhecimento histórico: uma história do saber escolar. 1993. Tese (Doutorado) Faculdade de Filosofia, Letras e Ciências Humanas, Universidade de São Paulo, 1993.

CERTEAU, Michel de. A invenção do cotidiano: arte de fazer. 5. ed. Petrópolis, RJ: Vozes, 1994.

CHARTIER, Roger. Práticas da leitura. São Paulo: Estação Liberdade, 1996.

CHEVALLARD, Y. La transposition didactique: du savoir savant au savoir ensigné. Grenoble: La Pensée Sauvage, 1991.

CHOPIN, Alain. Le manuel scolaire in cent references. Paris: Institut National de Recherche Pédagogique, 1992. 
DARNTON, Robert. O beijo de Lamourette. São Paulo: Companhia das Letras, 1992.

DEBORD, Guy. A sociedade do espetáculo. Rio de Janeiro: Contraponto, 2000 .

DEMO, Pedro. Politicidade: razão humana. Campinas, SP: Papirus, 2002.

ELIAS, Nobert. A sociedade dos indivíduos. Rio de Janeiro: Jorge Zahar 1994.

FOUCAULT, Michel. A ordem do discurso. 6. ed. São Paulo: Loyola, 2000.

FREIRE, Paulo. Política e educação: ensaio. São Paulo: Cortez, 1997.

FREITAG, B.; MOTA, V. R.; COSTA, W. F. O livro didático em questão. 3. ed. São Paulo: Cortez, 1997.

GALZERANI, Maria Carolina Bovério. Belas mentiras? A ideologia nos estudos sobre o livro didático. In: PINSKY, Jaime (Org.). O ensino de História e a criação do fato. São Paulo: Contexto, 1988.

LE GOFF, Jacques. História e memória. 4. ed. Campinas, SP: Ed. Unicamp, 1996.

LIMA, Paulo Gomes. A formação de professores: por uma ressignificação do trabalho pedagógico na escola. Dourados, MS: Ed. da UFGD, 2010.

LIMA, Paulo Gomes. Possibilidades ou potencialidades: qual a postura piagetiana na epistemologia genética sobre a gênese da inteligência? Campinas, SP: Ed. Unicamp, 1998.

MARTINS, Gilberto de Andrade. Manual para elaboração de monografia e dissertação. 2. ed. São Paulo: Atlas, 2002.

MORIN, Edgar. Os sete saberes necessários à educação do futuro. 5. ed. São Paulo: Cortez, 2002.

MORIN, Edgar. O método: as ideias: habitat, vida, costumes, organização (Tomo IV). Porto Alegre: Sulina, 1998.

MUNAKATA, Kazumi. Produzindo livros didáticos e paradidáticos. 1997. Dissertação (Mestrado em História e Filosofia da Educação) - Pontifícia Universidade Católica de São Paulo, 1997. 
PIAGET, Jean. Para onde vai a educação. Rio de Janeiro: José Olympio, 1973.

PIAGET, Jean. A formação do símbolo na criança. Rio de Janeiro: Zahar, 1973.

PIAGET, Jean. O desenvolvimento do raciocínio na criança. Rio de Janeiro: Record, 1977.

PIAGET, Jean. Epistemologia genética. São Paulo: Martins Fontes, 1983.

PIAGET, Jean. Psicogênese dos conhecimentos e seu significado epistemológico. In: PIATELLI-PALMARINI, M. (Org.). Teoria da linguagem/teoria da aprendizagem: o debate entre Jean Piaget e Noam Chomsky [ocorrido em 1975]. São Paulo: Cultrix, 1997.

THOMPSON, E. P. A miséria da teoria. Rio de Janeiro: Jorge Zahar, 1981.

UNIVERSIDADE DE CAMPINAS (Unicamp). Biblioteca Central. Serviço de Informação sobre o Livro Didático. O que sabemos sobre o livro didático: catálogo analítico. Campinas: Ed. da Unicamp, 1989. 221 p.

VIGOTSKI, Lev Semenovich. A formação social da mente: o desenvolvimento dos processos psicológicos superior. 6. ed. São Paulo: Martins Fontes, 2000.

ZAMBONI, Ernesta. História integrada é um eufemismo. Revista do Instituto Brasileiro de Edições Pedagógicas (IBEP) - Área de conhecimento: História, v. 1, n. 1, p. 8-11, mar. 2001.

Elício Gomes Lima, mestre em Educação pela Universidade Estadual de Campinas (Unicamp), é professor na rede pública (Estadual e Municipal) de ensino oficial do Estado de São Paulo. Desenvolve atividades docentes e pesquisas no Programa de Pós-Graduação em Educação Superior no Centro Universitário Adventista de São Paulo (Campus Engenheiro Coelho) com imersão em Políticas e Gestão Educacional, Formação de Professores, Planejamento e Projetos Educativos, Administração Escolar e Métodos e Prática de Ensino.

elicio.lima@bol.com.br

Recebido em 7 de outubro de julho de 2011.

Aprovado em 7 de novembro de 2012. 